\title{
PEMANFAATAN PURE PLANT OIL (PPO) DARI KELAPA SAWIT UNTUK MENGURANGI KONSUMSI BAHAN BAKAR SOLAR DI PLTD TALANG PADANG
}

\section{THE UTILIZATION OF PURE PLANT OIL (PPO) FROM PALM OIL TO REDUCE DIESEL FUEL CONSUMPTION OF DIESEL POWER GENERATOR IN TALANG PADANG}

\author{
Unggul Priyanto, Dwi Husodo Prasetyo, Erlan Rosyadi, Galuh Wirama Murti, \\ Zulaicha Dwi Hastuti, Novi Syaftika \\ Gedung Energi 625 Puspiptek Serpong, Indonesia \\ e-mail : unggul.priyanto@bppt.go.id, galuh.wirama@bppt.go.id
}

\begin{abstract}
Abstrak
Minyak nabati murni (Pure Plant Oill PPO) dari kelapasawit dapat digunakan sebagai subtitusi bahan bakar solar pada mesin diesel. PPO dapat digunakan dengan mencampurkannya dengan solar, sehingga mengurangi penggunaan bahan bakar fosil yang tidak ramah lingkungan. Akan tetapi, bahan bakar campuran PPO juga memiliki sisi negatif seperti Specific Fuel Consumption (SFC) yang tinggi, viskositas tinggi, nilai kalor yang rendah, dan emisi NOx yang cenderung sedikit lebih tinggi. Dalam studi ini berbagai campuran PPO dan solar diuji di PLTD. Hasilnya menunjukkan bahwa PPO sebaiknya digunakan dengan campuran solar dan proses pre-heating dilakukan sebelum masuk ke mesin. Penggunaan PPO juga teruji sebagai bahan bakar yang ramah lingkungan, kandungan sulfur yang rendah, serta menghasilkan emisi gas rumah kaca yang rendah. Agar PPO dapat digunakan pada mesin diesel, maka perlu beberapa perubahan seperti modifikasi mesin seperti pre-heating PPO, modifikasi sistem injektor, dual fuelling, dan blending PPO dengan solar.
\end{abstract}

Kata kunci : biofuel; PPO; kelapa sawit; PLTD; performa mesin diesel

\begin{abstract}
Pure Plant Oil (PPO) from palm oil can be used to subsitute diesel fuel for diesel engine. It can be used by mixing it with diesel so that the use of fossil fuel can be reduced. However, the mix of PPO and diesel fuel also have disadvantages such as high Specific Fuel Consumption (SFC), high viscosity, low calorific value, and slightly high $\mathrm{NO}_{x}$ emission. In this study, the use of mixed PPO and diesel fuel at various ratios in the diesel power generator were tested. The results show that PPO should be mixed with diesel fuel and preheating is necessary before it is injected to the engine. The use of PPO was also proved as environmentally friendly, low sulphur content, and emit lower green house gas emissions. In order to use PPO in diesel engine, the modification of the engine such as preheating device, injector system, dual fuelling system and PPO-diesel blending are necessary.
\end{abstract}

Key Words : biofuel; PPO; palm oil; diesel power generator; diesel engine performance

Diterima (received ) : 17 September 2019, Direvisi (revised ) : 15 November 2019 , Disetujui (accepted) : 03 Desember 2019 


\section{PENDAHULUAN}

Indonesia sangat bergantung pada sumber daya energi fosil dengan persentase konsumsi $95 \%$ dari total dan hanya $5 \%$ saja yang berasal dari sumber daya energi baru terbarukan (seperti hidro dan geotermal) pada 20151). Berdasarkan Peraturan Presiden No. 5/2006, pemerintah Indonesia berkomitmen untuk mengurangi pemakaian sumberdaya energi fosil yaitu minyak bumi dan gas alam hingga $50 \%$ pada tahun $2025^{2}$. Diharapkan pada 2025, paling tidak $17 \%$ dari total bauran energi utama dipenuhi dari energi baru terbarukan yaitu biofuel $(5 \%)$, geotermal $(5 \%)$, pencairan batubara $(2 \%)$, dan lain-lain seperti nuklir, pembakaran langsung biomassa, tenaga hidro, tenaga surya, dan tenaga angin (5\%). Hal ini diperkuat oleh Peraturan Presiden nomor 22/2017 yang menetapkan target bauran energi baru terbarukan sebesar $23 \%^{33}$. Oleh karena itu, strategi untuk mencapai target tersebut perlu disusun diantaranya dengan memanfaatkan minyak nabati sebagai campuran bahan bakar fosil untuk Pembangkit Listrik Tenaga Diesel (PLTD).

Minyak nabati murni atau Pure Plant Oil (PPO) berasal dari minyak tumbuhtumbuhan yang dimurnikan tanpa adanya perubahan kimia. Minyak nabati mentah perlu dipisahkan terlebih dahulu dari pengotor-pengotornya seperti getah (gum), asam lemak bebas (ALB), dan logam-logam alkali agar tidak merusak mesin ${ }^{4}$. PPO berbeda dengan biodiesel karena komponen dalam biodiesel sudah melalui reaksi transesterifikasi dengan metanol yang menghasilkan produk fatty acid methyl ester (FAME), sedangkan PPO tidak. Gambar 1 menunjukkan diagram alir proses PPO dan biodiesel untuk mesin diesel. PPO berpotensi lebih ekonomis dan memiliki jejak karbon yang lebih baik daripada biodiese ${ }^{5}$. Namun, bahan bakar PPO ini jarang digunakan karena viskositas tinggi dan volatilitas rendah sehingga menyebabkan emisi partikulat tinggi dari pembakaran yang tidak sempurna, atomisasi bahan bakar yang buruk, masalah lain seperti perawatan, karbonisasi di ring, dan sumbatan deposit pada injektor ${ }^{6}$. Oleh karena itu, perlu adanya modifikasi pada umpan bahan bakar sebelum masuk ke mesin berupa preheating.

Parameter-parameter yang penting dalam penggunaan minyak nabati sebagai bahan bakar adalah, bilangan iodin (iodine number), titik kabut (cloud point), titik tuang (pour point), dan angka setana (cetane

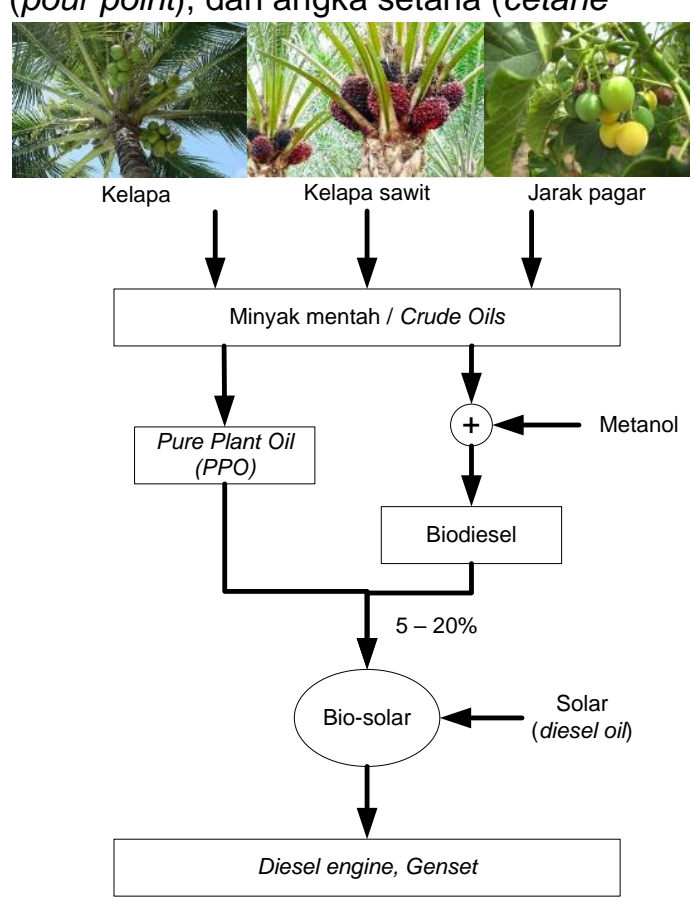

Gambar 1.

Diagram Alir Proses PPO dan Biodiesel (FAME)

number). Bilangan iodin menunjukkan besarnya jumlah asam lemak jenuh dan tak jenuh dalam minyak. Umumnya, semakin besar bilangan iodin maka asam lemak tak jenuhnya semakin banyak dan tidak baik untuk bahan bakar7). Sedangkan titik kabut dan titik tuang minyak nabati merupakan parameter yang sangat penting khususnya di area subtropis karena akan mempengaruhi aliran bahan bakar ke mesin ${ }^{8}$. . Adapun angka setana bahan bakar diharapkan mempunyai nilai yang besar agar lebih mudah terbakar saat bercampur dengan udara di ruang bakar ${ }^{9}$.

Sebagaimana yang ditampilkan pada Tabel 1, minyak sawit memiliki bilangan iodin yang rendah sehingga cocok digunakan sebagai bahan bakar. Namun, titik tuang dan titik beku PPO dari sawit yang tinggi merupakan kelemahan dari bahan bakar ini. Akan tetapi, hal ini tidak berpengaruh bila digunakan di area yang beriklim tropis. Selain itu, PPO dari sawit mempunyai angka setana yang tinggi sehingga sangat diminati sebagai bahan bakar.

Dalam skala laboratorium telah banyak dilakukan uji coba pencampuran PPO dengan High Speed Diesel (HSD) atau solar pada mesin diesel ${ }^{10), 11)}$. Namun, masih sedikit sekali studi literatur tentang performa mesin diesel pada skala besar seperti PLTD 
Pemanfaatan Pure Plant Oil (PPO) Dari Kelapa Sawit Untuk Mengurangi Konsumsi Bahan Bakar Solar Di PLTD Talang Padang (Unggul Priyanto, Dwi Husado P., Erlan Rosyadi, galuh Wirama Murti, Zulaicha Dwi hastuti, Novi Syaftika)

dengan bahan bakar PPO ini. Oleh karena itu, dalam studi ini penggunaan campuran PPO dan solar pada performa operasi mesin diesel pada PLTD dieksplorasi. Keamanan dan stabilitas mesin diesel yang menggunakan campuran bahan bakar PPO dan solar pada pembangkit listrik tenaga diesel pun diuji. Uji viskositas dari beberapa perbandingan campuran PPO sawit dan solar juga diamati pada beberapa titik suhu yang berbeda. Hal ini penting dilakukan untuk menentukan pra-pemanasan (pre- heating) sebelum bahan bakar campuran tersebut masuk ke ruang pembakaran.

Pengujian performa PPO pada mesin diesel ini bertujuan untuk mengetahui karakteristik pembakaran bahan bakar PPO dibandingkan dengan bahan bakar fosil berupa solar. Parameter-parameter yang akan dibandingkan adalah konsumsi bahan bakar spesifik/ specific fuel consumption (SFC), emisi, Brake Thermal Efficiency terhadap Brake Power, dan pengaruh kecepatan terhadap tenaga mesin.

Tabel 1

Karakteristik berbagai minyak nabati dan lemak

\begin{tabular}{|c|c|c|c|c|c|c|c|}
\hline \multirow[b]{2}{*}{ Minyak/Lemak } & \multicolumn{7}{|c|}{ Parameter } \\
\hline & Bilanganlodin & ngkaSetana & $\begin{array}{c}\text { Nilai } \\
\text { kalor } \\
(\mathrm{kJ} / \mathrm{kg})\end{array}$ & $\begin{array}{l}\text { Viskositas } \\
\left(\mathrm{mm}^{2} / \mathbf{s}\right)\end{array}$ & $\begin{array}{l}\text { TitikKabut } \\
\left({ }^{\circ} \mathrm{C}\right)\end{array}$ & $\begin{array}{l}\text { TitikTuang } \\
\left({ }^{\circ} \mathrm{C}\right)\end{array}$ & $\begin{array}{c}\text { Titik } \\
\text { Nyala } \\
\left({ }^{\circ} \mathrm{C}\right)\end{array}$ \\
\hline Babassu & $10-18$ & 38 & - & - & - & - & - \\
\hline Jarak & $82-88$ & - & 39.500 & 297 (38 C) & - & $-31,7$ & 260 \\
\hline Kelapa & $6-12$ & - & - & - & - & - & - \\
\hline Jagung & $103-140$ & 37,6 & 39.500 & 34,9 (38 C) & $-1,1$ & $-40,0$ & 277 \\
\hline BijiKapuk & $90-119$ & 41,8 & 39.468 & $33,5(38 \mathrm{C})$ & 1,7 & $-15,0$ & 234 \\
\hline Crambe & 93 & 44,6 & 40.482 & 53,6 (38 C) & 10,0 & $-12,2$ & 274 \\
\hline Linseed & $168-204$ & 34,6 & 39.307 & $27,2(38 \mathrm{C})$ & 1,7 & $-15,0$ & 241 \\
\hline Olive & $75-94$ & - & - & - & - & - & - \\
\hline Kelapasawit & $35-61$ & $42-49$ & 40.100 & - & - & - & $267-304$ \\
\hline Kacang & $80-106$ & 41,8 & 39.782 & $39,6(38 \mathrm{C})$ & 12,8 & $-6,7$ & 271 \\
\hline Rapeseed & $94-120$ & 37,6 & 39.709 & $37,0(38 \mathrm{C})$ & $-3,9$ & $-31,7$ & 246 \\
\hline Safflower & $126-152$ & 41,3 & 39.519 & $31,3(38 \mathrm{C})$ & 18,3 & $-6,7$ & 260 \\
\hline High-oleic safflower & $90-100$ & 49,1 & 39.516 & $41,2(38 \mathrm{C})$ & $-12,2$ & $-20,6$ & 293 \\
\hline Wijen & $104-120$ & 40,2 & 39.349 & 35,5 (38 C) & $-3,9$ & $-9,4$ & 260 \\
\hline Bijikedelai & $117-143$ & 37,9 & 39.623 & 32,6 (38 C) & $-3,9$ & $-12,2$ & 254 \\
\hline Bijibungamatahari & $110-143$ & 37,1 & 39.575 & $37,1(38 \mathrm{C})$ & 7,2 & $-15,0$ & 274 \\
\hline Tallow & $35-48$ & - & 40.054 & $\begin{array}{c}51,15(40 \\
\mathrm{C})\end{array}$ & - & - & 201 \\
\hline No. 2 DF & - & 47 & 45.343 & $2,7(38 \mathrm{C})$ & $-15,0$ & $-33,0$ & 52 \\
\hline
\end{tabular}

\section{BAHAN DAN METODE}

Pengujian performa mesin diesel ini dilaksanakan di PLTD Talang Padang, Lampung selama 3 (tiga) bulan. Gambar 2 menunjukkan mesin diesel nomor 3 yang ada di PLTD Talang Padang. Spesifikasi mesin diesel yang digunakan pada uji coba ditunjukkan pada Tabel 2. PLTD ini memiliki daya terpasang $270 \mathrm{~kW}$.

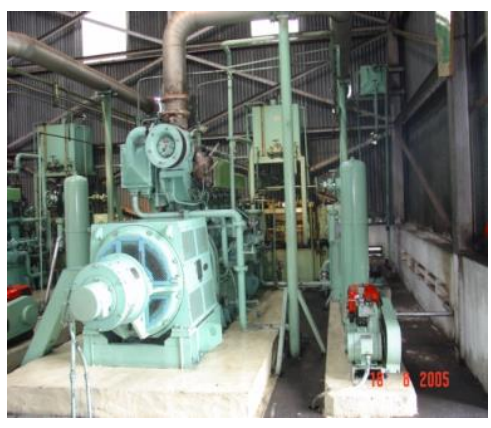

Gambar 2.

PLTD Talang Padang, Lampung

Uji viskositas dilakukan dengan menggunakan beberapa sampel campuran PPO sawit dan solar dengan perbandingan volume $30,40,50,70 \%$, dan $100 \%$ PPO pada rentang suhu $25-75^{\circ} \mathrm{C}$. Uji viskositas ini dilakukan dengan viskometer sesuai dengan metode ASTM D-445 ${ }^{12)}$.

Tabel 2.

Spesifikasi PLTD di Talang Padang Lampung

\begin{tabular}{ll}
\hline \multicolumn{1}{c}{ Spesifikasi } & Data Teknis \\
\hline Daya terpasang & $270 \mathrm{~kW}$ \\
Silinder & 6 \\
Cylinder bore & $200 \mathrm{~mm}$ \\
Stroke & $240 \mathrm{~mm}$ \\
Firing order & $1-5-3-6-2-4-1$ \\
Kecepatan mesin & $750 \mathrm{rpm}$ \\
Tahun mesin & 1982 \\
\hline
\end{tabular}


Pemantauan dan sumber data untuk mengetahui performa operasi ditunjukkan pada Tabel 3. SFC dihitung dari laju alir sampel bahan bakar dengan flow meter yang terpasang di pipa umpan ke mesin diesel dan dibandingkan terhadap daya yang dihasilkan oleh $\mathrm{kWh}$ meter yang ada di ruang kontrol. Pemantauan dilakukan setiap interval 1 jam.

Tabel 3.

Parameter performa operasi

\begin{tabular}{ll}
\hline \multicolumn{1}{c}{ Item } & \multicolumn{1}{c}{ Sumber Data } \\
Pemantauan & \\
\hline Loading & Data logger dari ruang \\
Performance & kontrol \\
Specific Fuel & Laju alir yang diambil dari \\
Consumption & flowmeter / flow counter dan \\
(SFC) & kWh meter dari ruang kontrol \\
Uji Emisi & Flue gas duct \\
Performance & Data logger dari ruang \\
Diesel & kontrol \\
Power & Data logger dari ruang \\
& kontrol \\
\hline
\end{tabular}

Pengujian tingkat emisi dilakukan dengan mengukur kandungan emisi pada flue gas. Uji ini umumnya dilakukan pada dua atau tiga jam setelah operasi mesin diesel stabil. Polutan udara dikarakterisasi menggunakan alat analisis yaitu spetrofotomerik dan gas analyzer.

Fasilitas blending PPO dan solar dibangun untuk mendukung kegiatan ini dan posisinya terletak sebelum bahan bakar masuk ke mesin diesel. Diagram alir berwarna biru menunjukkan fasilitas blending PPO yang ditambahkan pada PLTG Talang Padang dan yang berwarna hitam merupakan fasilitas existing di lapangan. Dengan adanya fasilitas blending ini, sampel bahan bakar dicampur secara homogen dan pre-heating diatur pada suhu tertentu $\left(70^{\circ} \mathrm{C}\right)$. Gambar 3 mengilustrasikan fasilitas blending yang dibangun di PLTD Talang Padang, Lampung.

Rasio blending PPO dan solar adalah rasio volumetrik yang diatur oleh valve flow meter nomor 3 dan nomor 1 (Gambar 3).
Kemudian sebelum masuk ke mesin, dilakukan pre-heating pada suhu yang telah ditentukan tergantung rasio PPO/solar.

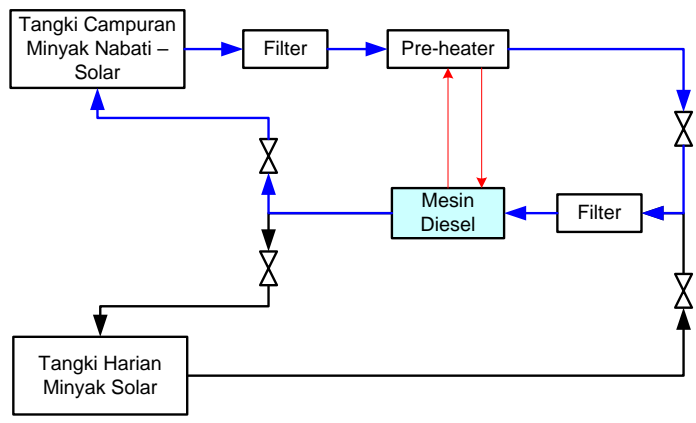

Gambar 3.

Sistem fasilitas blending PPOdan solar dengan kapasitas 1 ton per batch

Dalam studi ini spesifikasi bahan bakar PPO dan solar telah diuji oleh laboratorium dengan standar SNI 7431:200813) yang ditunjukkan pada Tabel 4.

Tabel 4.

Karakteristik bahan bakar Solar dan PPO

\begin{tabular}{cccccc}
\hline No & Parameter & Satuan & Solar & \multicolumn{1}{c}{ PPO } & Batas \\
\hline 1 & Nilai Kalor & $\mathrm{kcal} / \mathrm{kg}$ & 10.665 & 9.402 & \\
2 & Ash Content & $\%$ wt & $<0.002$ & 0.001 & Maks 0.02 \\
& $\mathrm{Si}$ & $\mathrm{mg} / \mathrm{kg}$ & 51.42 & $<0.01$ & \\
& $\mathrm{Fe}$ & $\mathrm{mg} / \mathrm{kg}$ & 2.52 & 4.78 & \\
$\mathrm{Al}$ & $\mathrm{mg} / \mathrm{kg}$ & Trace & 1.21 & \\
$\mathrm{Ca}$ & $\mathrm{mg} / \mathrm{kg}$ & 1.37 & 1.17 & \\
$\mathrm{Mg}$ & $\mathrm{mg} / \mathrm{kg}$ & 1.71 & 1.27 & \\
$\mathrm{~K}$ & $\mathrm{mg} / \mathrm{kg}$ & 3.16 & 12.09 & \\
$\mathrm{Na}$ & $\mathrm{mg} / \mathrm{kg}$ & 13.52 & 53.5 & \\
$\mathrm{Mn}$ & $\mathrm{mg} / \mathrm{kg}$ & 0.17 & Trace & \\
$\mathrm{Ti}$ & $\mathrm{mg} / \mathrm{kg}$ & 14.77 & Trace & \\
& $\mathrm{SO} 4$ & $\mathrm{mg} / \mathrm{kg}$ & Trace & $<0.01$ & \\
& $\mathrm{Ba}$ & $\mathrm{mg} / \mathrm{kg}$ & Trace & 5.9 & \\
& $\mathrm{Sr}$ & $\mathrm{mg} / \mathrm{kg}$ & Trace & $<0.01$ & \\
3 & Sulfur Content & $\% \mathrm{wt}$ & 0.09 & $<0.015$ & \\
4 & Water Content & $\% \mathrm{wt}$ & $<0.05$ & 0.037 & Maks 0.075 \\
5 & Sedimen & $\% \mathrm{wt}$ & 0.004 & 0.007 & \\
\hline & & & & &
\end{tabular}

Bahan bakar campuran yang digunakan ini harus sesuai dengan ASTM D 975 tentang "Requirement for Diesel Fuel". Hal ini dilakukan untuk meminimalkan efek dari modifikasi bahan bakar dengan pencampuran PPO. Tabel 5 menunjukkan batasan untuk lima kategori bahan bakar mesin diesel sesuai dengan ASTM.

Tabel 5

Klasifikasi bahan bakar mesin diesel berdasarkan ASTM D 975

\begin{tabular}{|c|c|c|c|c|c|c|c|}
\hline \multirow[b]{2}{*}{ Karakteristik } & \multirow[b]{2}{*}{ Metode } & \multirow[b]{2}{*}{ Satuan } & \multicolumn{5}{|c|}{ Kategori } \\
\hline & & & $\begin{array}{l}\text { Low } \\
\text { sulfur }\end{array}$ & \#1-D & $\begin{array}{l}\text { Low sulfur } \\
\text { \#2-D }\end{array}$ & \#2-D & \#4-D \\
\hline Flash Point & D 93 & ${ }^{\circ} \mathrm{C}$ & 37,8 & 37,8 & 52,2 & 52,2 & 55 \\
\hline $\begin{array}{l}\text { Viskositas kinetik, } 40 \\
{ }^{\circ} \mathrm{C}\end{array}$ & D 445 & cSt & $1,3-2,4$ & $1,3-2,4$ & $1,9-4,1$ & $1,9-4,1$ & $5.5-24$ \\
\hline Ash Content & D 482 & $\%$ & 0,01 & 0,01 & 0,01 & 0,01 & 0,1 \\
\hline Sulfur Content & D2622 & $\%$ & 0,05 & 0,5 & 0,05 & 0,05 & 2,0 \\
\hline Water and Sediment & D 2709 & $\%$ & 0.05 & 0.05 & 0.05 & 0,05 & 0,05 \\
\hline
\end{tabular}


Pemanfaatan Pure Plant Oil (PPO) Dari Kelapa Sawit Untuk Mengurangi Konsumsi Bahan Bakar Solar Di PLTD Talang Padang (Unggul Priyanto, Dwi Husado P., Erlan Rosyadi, galuh Wirama Murti, Zulaicha Dwi hastuti, Novi Syaftika)

\section{HASIL DAN PEMBAHASAN}

\section{Viskositas dan Penentuan Suhu Bahan Bakar}

Pencampuran PPO dengan solar akan mempengaruhi viskositas. Dalam studi ini pencampuran PPO dengan solar disertai dengan uji vikositas pada kenaikan suhu setiap $5^{\circ} \mathrm{C}$ untuk mengetahui suhu bahan bakar yang dikehendaki. Pemanasan bahan bakar yang melebihi suhu batas operasional dapat menyebabkan kerusakan komponen pompa injeksi. Target pemanasan bahan bakar ini harus sesuai dengan viskositas bahan bakar yang diperbolehkan pada mesin, dalam hal ini sekitar 1,9-4,1 cSt pada $40^{\circ} \mathrm{C}$. Viskositas solar murni $100 \%$ sekitar $3,86 \mathrm{cSt}$ pada $40^{\circ} \mathrm{C}$. Gambar 4 menunjukkan pengaruh suhu terhadap viskositas campuran PPO dan solar.

Semakin tinggi suhu bahan bakar, maka semakin rendah viskositasnya. Sedangkan, viskositas semakin bertambah bila rasio PPO terhadap solar semakin besar. Kenaikan viskositas menyebabkan menurunnya kualitas pengkabutan dan pembakaran. Dalam beberapa studi menunjukkan bahwa viskositas akan mempengaruhi kualitas atomisasi dimana viskositas menurun sesuai dengan fungsi suhu ${ }^{14), 15)}$. Untuk mengurangi dampak dari viskositas yang tinggi, maka pada sampel bahan bakar $50 \%$ PPO dan $50 \%$ solar preheating dilakukan pada suhu $70^{\circ} \mathrm{C}$ dengan nilai viskositas sekitar 5,8 cSt.

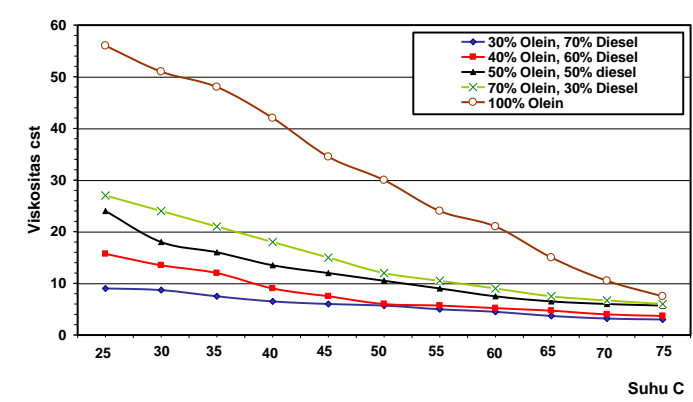

Gambar 4

Pengaruh suhu terhadap viskositas campuran PPO dan solar.

Studi yang dilakukan oleh Lance, dkk (2004) menunjukkan adanya hubungan viskositas terhadap emisi NOx ${ }^{16}$. Semakin tinggi viskositas maka semakin tinggi produksi NOx. Densitas dan bilangan iodin yang tinggi menyebabkan pembentukan
NOx ${ }^{17)}$. Hal ini disebabkan minyak dengan asam lemak polyunsaturated yang tinggi cenderung menyebabkan produksi emisi NOx yang tinggi. Sehingga minyak dengan asam lemak polyunsaturated rendah seperti kelapa dan kelapa sawit akan membentuk NOx yang sedikit.

\section{Hasil Uji Performa Daya Mesin Diesel terhadap Specific Fuel Consumption (SFC)}

Performa operasi mesin diesel dipengaruhi oleh perubahan bahan bakar dengan pencampuran dengan PPO. Gambar 5 menunjukkan pengaruh Brake Horse Power (BHP) terhadap SFC dengan variasi beberapa sampel bahan bakar. Sampel bahan bakar yang diuji adalah $100 \%$ solar dan $10 \%$ PPO $+90 \%$ solar tanpa didahului dengan pemanasan, sedangkan sampel bahan bakar $50 \%$ PPO+50\% solar disertai pemanasan awal pada $70^{\circ} \mathrm{C}$.

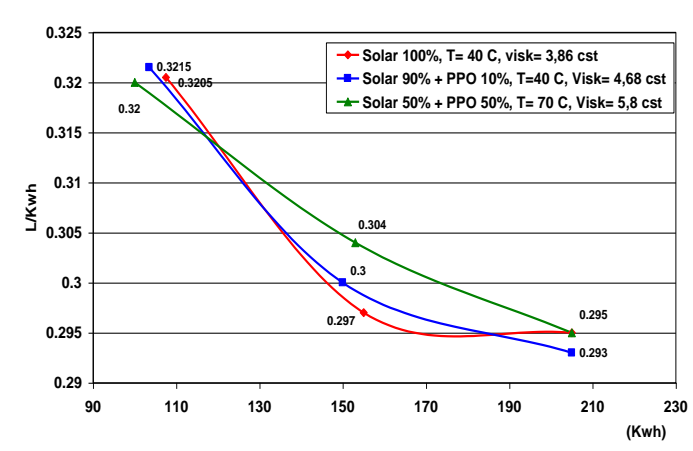

Gambar 5.

Pengaruh Brake Horse Power (BHP) terhadap Specific Fuel Consumption (SFC)

Pada daya rendah sekitar $110 \mathrm{kWh}$ nilai SFC bahan bakar campuran hampir sama dengan solar $100 \%$. Namun, semakin tinggi daya digunakan, terlihat jelas SFC bahan bakar dengan campuran PPO lebih tinggi dari solar. Terlihat pada SFC yang meningkat pada penggunaan sampel bahan bakar $50 \%$ PPO $+50 \%$ solar disertai pemanasan awal pada $70^{\circ} \mathrm{C}$. Konsumsi bahan bakar dengan campuran PPO dapat lebih tinggi dan mencapai $\pm 3 \%$ daripada dengan solar $100 \%$. Hal ini disebabkan nilai kalor bahan bakar yang menurun akibat adanya PPO dalam campuran yang mempunyai nilai kalor di bawah solar (nilai kalor PPO $9.402 \mathrm{kcal} / \mathrm{kg}$ < solar 10.665 $\mathrm{kcal} / \mathrm{kg}$ ) sebagaimana ditampilkan pada pada Tabel 4. Studi lain menunjukkan hal yang sama dimana nilai kalor rendah sehingga meningkatkan konsumsi bahan bakar6),10),17). 


\section{Hasil Uji Emisi PLTD pada Penggunaan $50 \%$ PPO + $50 \%$ Solar}

Tabel 6 menunjukkan hasil uji emisi antara solar $100 \%$ dengan $50 \%$ PPO $+50 \%$ solar pada mesin diesel. Terdapat sedikit kenaikan emisi $\mathrm{NO}_{2}$ pada penggunaan $50 \%$ PPO $+50 \%$ solar. Hasil yang sama juga ditemukan dalam berbagai studi(18),19,20),21),22). Hal ini disebabkan karena viskositas dan densitas yang tinggi membuat minyak nabati atau PPO berada lebih lama dalam ruang bakar daripada solar. Penundaan penyalaan meningkatkan panjang nyala api sehingga lebih banyak bahan bakar yang terbakar di belakang spray. Pembakaran terjadi lebih dekat ke dinding silinder dan mungkin lebih melebihi porsi ruang bakar. Keberadaan oksigen dalam molekul PPO dapat meningkatkan reaksi kimia dengan $\mathrm{N}_{2}$ dari udara sehingga terbentuk NO. Kecenderungan polimerisasi asam lemak dapat menyebabkan akumulasi NO sebagai deposit dalam ruang pembakaran ${ }^{22}$.

Tabel 6.

Perbandingan emisi pada mesin 3 dengan bahan bakar solar 100\% dan 50\% PPO +50\% solar di PLTD Talang Padang

\begin{tabular}{|c|c|c|c|c|c|}
\hline \multirow[b]{2}{*}{ Parameter } & \multirow[b]{2}{*}{ Satuan } & \multicolumn{2}{|c|}{ Mesin 3} & \multirow{2}{*}{$\begin{array}{c}\text { Baku Mutu } \\
\text { Kep-13 } \\
\text { MENLH/3/95 }\end{array}$} & \multirow[b]{2}{*}{ Alat Analisis } \\
\hline & & Solar & $\begin{array}{l}50 \% \text { PPO+ } \\
50 \% \text { Solar }\end{array}$ & & \\
\hline Nitrogen dioksida $\left(\mathrm{NO}_{2}\right)$ & $\mathrm{mg} / \mathrm{m}^{3}$ & 26,5 & 32,6 & 1000 & Spetrofotometrik \\
\hline Sulfur dioksida $\left(\mathrm{SO}_{2}\right)$ & $\mathrm{mg} / \mathrm{m}^{3}$ & 60,53 & 1,1 & 800 & Spetrofotometrik \\
\hline Karbon monoksida (CO) & ppm & 3,46 & 2,9 & - & Gas Analyzer \\
\hline Karbon dioksida $\left(\mathrm{CO}_{2}\right)$ & $\%$ & 12,93 & 10,42 & - & Gas Analyzer \\
\hline
\end{tabular}

Penurunan drastis jumlah emisi $\mathrm{SO}_{2}$ dari $60,53 \mathrm{ke} 1,1 \mathrm{mg} / \mathrm{m}^{3}$ karena PPO atau minyak nabati mengandung sulfur yang sangat kecil. Beberapa studi juga mengungkapkan hal yang sama, emisi $\mathrm{SO}_{2}$ cenderung menurun pada penggunaan PPO untuk mesin diesel21),23)

Jumlah emisi $\mathrm{CO}$ dan $\mathrm{CO}_{2}$ mengalami sedikit penurunan. Emisi rendah karena mencampur PPO dengan solar, maka jumlah karbon yang rendah dan kandungan oksigen yang tinggi dalam molekul bahan bakar dibandingkan dengan petro-diese ${ }^{21}$. Hasil ini kontradiksi dengan beberapa studi yang lain yang mendapatkan jumlah emisi CO lebih tinggi daripada petro-diesel| ${ }^{19), 24) .}$

\section{Hasil Uji Performa Brake Thermal Efficiency terhadap Brake Power}

Gambar 6 menunjukkan Brake Themal Efficiency terhadap Brake Power dengan menggunakan beberapa bahan bakar campuran PPO (10, 50, 70, dan $100 \%$ ). Solar murni menunjukkan nilai yang paling tinggi diantara yang lain.

Kemudian dikuti oleh 10\% PPO + 90\% solar karena 10\% PPO memiliki karakteristik semprotan yang lebih baik dalam ruang bakar sehingga mendapatkan udara secara efektif dan menghasilkan pembakaran yang lebih sempurna ${ }^{25}$

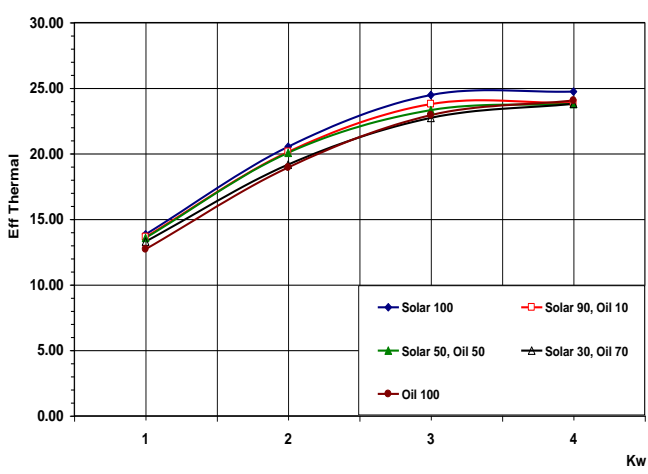

Gambar 6.

Perbandingan beberapa bahan bakar pada efisiensi termal terhadap daya

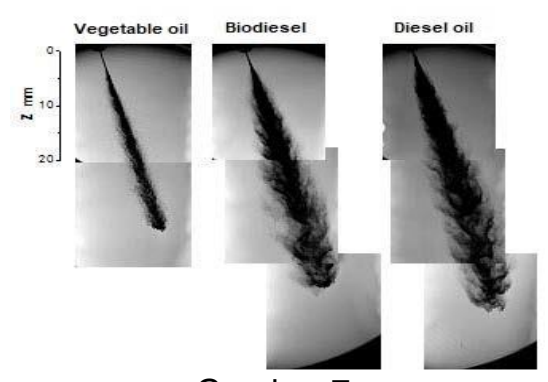

Gambar 7.

Perbandingan karakteristik semprotan antara minyak nabati/PPO, biodiesel, dan diesel oil/solar pada kondisi operasi suhu $25^{\circ} \mathrm{C}$, tekanan injektor 400 bar, dan waktu $0,5 \mathrm{~ms}$ (diadaptasi dari Adam dkk., 2012 ${ }^{26}$ ) 
Pemanfaatan Pure Plant Oil (PPO) Dari Kelapa Sawit Untuk Mengurangi Konsumsi Bahan Bakar Solar Di PLTD Talang Padang (Unggul Priyanto, Dwi Husado P., Erlan Rosyadi, galuh Wirama Murti, Zulaicha Dwi hastuti, Novi Syaftika)

Berdasarkan Gambar 7, terlihat bahwa penetrasi semprotan PPO lebih pendek daripada biodiesel dan solar. Terlebih lagi pola PPO atau minyak nabati dengan sudut kerucut semprotan yang sempit dari ujung nozzle hingga area ujung semprot. Hal ini disebabkan karena tingginya viskositas PPO daripada biodiesel dan solar sehingga mempengaruhi karakteristik kinerja bentuk semprotannya ${ }^{26)}$.

Modifikasi injektor dapat dilakukan dengan mengurangi tekanan pembukaan jarum injektor sebesar $20 \%{ }^{27}$. Hal tersebut mempengaruhi kinerja injektor dan mengurangi jumlah coke yang terbentuk pada ujung injektor.

\section{Pengaruh Kecepatan Mesin terhadap Daya Mesin dengan bahan bakar 10\% PPO + $90 \%$ Solar}

Pengaruh kecepatan mesin dengan bahan bakar menggunakan PPO dan solar murni terhadap daya dan torsi ditunjukkan pada Gambar 8. Secara umum, daya dan torsi mesin lebih rendah daripada solar ketika mengunakan bahan bakar dengan campuran PPO. Hal ini disebabkan pembentukan campuran dan pembakaran yang tidak sempurna, karena nilai kalor yang rendah dan viskositas yang tinggi. Kecenderungan hasil yang diperoleh beberapa studi lain juga hampir sama. Sebagai contoh, penggunaan minyak goreng bekas menunjukkan daya dan torsi lebih rendah daripada petrodiesel ${ }^{18)}$.

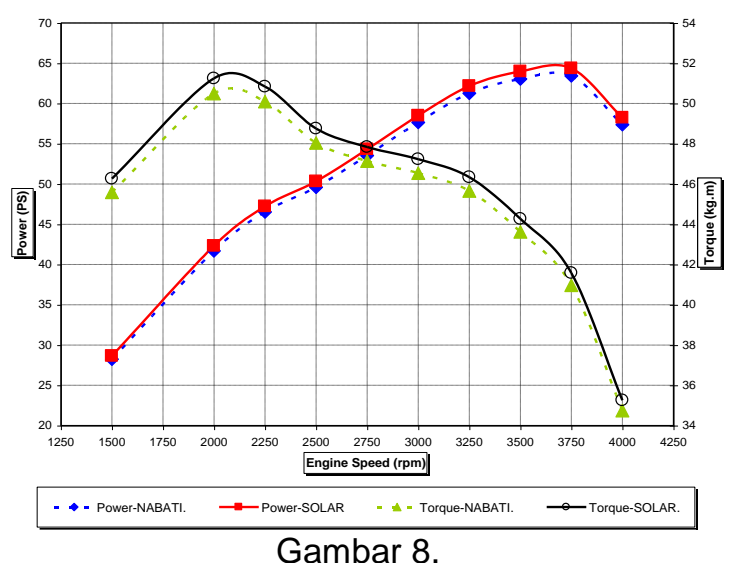

Pengaruh beberapa bahan bakar pada kecepatan mesin terhadap daya dan torsi

Pada kecepatan rpm tinggi, perbedaan antara bahan bakar solar dan PPO menjadi besar. Perbedaan dalam torsi cenderung ditentukan oleh kandungan kalori atau komposisi minyak sawit. Nilai kalor PPO sawit sekitar $13 \%$ lebih rendah dibanding minyak diesel mineral seperti solar.

\section{SIMPULAN}

Penggunaan PPO sebagai bahan bakar memiliki keunggulan dalam hal ramah lingkungan, kandungan sulfur yang rendah, mengurangi emisi gas rumah kaca. Agar PPO dapat digunakan pada mesin diesel, maka perlu beberapa perubahan seperti modifikasi mesin seperti pre-heating PPO, modifikasi sistem injektor, dual fuelling, dan blending PPO dengan solar.

Pemanfaatan PPO menyebabkan viskositas bahan bakar menjadi lebih tinggi, SFC yang lebih tinggi, emisi $\mathrm{NO}_{2}$ meningkat dibandingkan solar. Akan tetapi, pengunaan $50 \%$ PPO $+50 \%$ solar lebih ramah terhadap lingkungan dikarenakan bersifat karbon netral serta emisi $\mathrm{SO}_{2}, \mathrm{CO}$, dan $\mathrm{CO}_{2}$-nya lebih rendah daripada solar $100 \%$. PPO sawit dapat dijadikan salah satu alternatif energi untuk mesin diesel khususnya di Indonesia yang kaya akan komoditas sawit.

\section{UCAPAN TERIMA KASIH}

Terima kasih kami ucapan kepada rekanrekan tim PPO di PTSEIK BPPT atas dedikasi pikiran dan waktu dalam menyelesaikan kegiatan ini dengan baik dan tim PT PLN Talang Padang yang telah membantu kelancaran studi ini hingga selesai.

\section{DAFTAR PUSTAKA}

1. http://ebtke.esdm.go.id/post/2018/03/01 /1899/peluang.investasi.efisiensi.energi. masih.cukup.besar (Diakses pada Agustus 2019).

2. Peraturan Presiden No. $5 / 2006$

3. Peraturan Presiden No. 22/2017

4. EMA, Use of raw vegetable oil or animal fats in diesel engines, Switzerland, November 2004.

5. Prihandana, R., Hambali, E., Mujdalipah, S., Hendroko, R., Meraup Untung dari Jarak Pagar. Agromedia Pustaka, 2007.

6. Hu Li, Biller, P., Hadavi, S. A., Andrews, G. E., Przybyla, G., Langton, A. L., Assessing combustion and emission performance of direct use of SVO in a diesel engine by oxygen enrichment of intake air method, Biomass and Bioenergy, vol. 51, 2013, p. 43-52 
7. Samara Soares Fábio R. P. Rocha, Fast Spectrophotometric Determination of lodine Value in Biodiesel and Vegetable Oils, Journal of the Brazilian Chem. Soc. vol. 29 no.8 Aug. 2018

8. A.Akhil, M.A. Koya, S. Akhilesh, M.C.A. Ashif, S. Khan, R. Kanna, Determination of Cloud and Pour Point of Various Petroleum Products. International Refereed Journal of Engineering and Science (IRJES). 2017.

9. J.B. Heywood, Internal Combustion Engine Fundamentals; McGraw-Hill: New York, NY, USA, 1988.

10. R.D. Misra, M.S. Murthy, Straight vegetable oils usage in a compression ignition engine-A review, Renewable and Sustainable Energy Reviews, vol. 14, p. 3005-3013, 2010

11. S.S. Sidibe, J. Blin, G. Vaitilingom, Y. Azoumah, Use of crude filtered vegetable oil as a fuel in diesel engines state of the art: Literature review, Renewable and Sustainable Energy Reviews, vol. 14, p. 2748-2759, 2010

12. Standard Test Method for Kinematic Viscosity of Transparent and Opaque Liquids (and Calculation of Dynamic Viscosity). An American National Standard British Standard 2000: Part 71:1990.

13. http://bsn.go.id/

14. J.L.H.P. Salleveltet al, The impact of spray quality on the combustion of a viscous biofuel in a micro gas turbine, Applied Energy, vol. 132, no.1, pp. 575585, Nov. 2014.

15. J.L.H.P. Sallevelt, A.K. Pozarlik, G Brem, Characterization of viscous biofuel sprays using digital imaging in the near field region, Applied Energy 147 (2015) 161-175, 2015

16. Lance DL, Andersson JD, Emissions performance of pure vegetable oil in two European light duty vehicles, SAE paper 2004-01-1881. 2004.

17. Soo-Young No, Application of straight vegetable oil from triglyceride-based biomass to IC engines - A review, Renewable and Sustainable Energy Reviews, Vol. 69, Pages 80-97, 2017

18. D. Capuano, M. Costa, S. Di Fraia, N. Massarotti, L. Vanoli, Direct use of waste vegetable oil in internal combustion engines, Renewable and Sustainable Energy Reviews, vol. 69 759-770, 2017
19. Hribernik A, Kegl B., Performance and exhaust emissions of an indirectinjection (IDI) diesel engine when using waste cooking oil as fuel, Energy Fuels vol. 23 (3), p. 1754-8, 2009

20. Alessandro Corsinia, Giacomo Fanfarilloa, Franco Rispolia, Paolo Venturini, Pollutant emissions in common-rail Diesel engines in extraurban cycle: rapeseed oils vs Diesel fuel. Energy Procedia 82, p. 141 $-148,2015$

21. Namliwan $\mathrm{N}$, Wongwuttanasatian $\mathrm{T}$. Performance of diesel engine using diesel B3 mixed with crude palm oil. Sci World J 2014, 2014

22. Bari S, Yu C, Lim T. Effect of fuel injection timing with waste cooking oil as a fuel in a direct injection diesel engine, In: Proceedings of the Institution of Mechanical Engineers, Part D: Journal of Automobile Engineering, vol. 218 (1), p. 93-104, 2004

23. D'Alessandro B, et al. Straight and waste vegetable oil in engines: review and experimental measurement of emissions, fuel consumption and injector fouling on a turbocharged commercial engine. Fuel, vol. 182, p. 198-209, 2016

24. Wang $Y$, et al. An experimental investigation of the performance and gaseous exhaust emissions of a diesel engine using blends of a vegetable oil. Appl Therm Eng, vol. 26(14), p. 168491, 2006

25. V. Manieniyan, R.Senthilkumar, and S. Sivaprakasam, Experimental Investigation on Optimized Biodiesel (Based on Various Catalysts) used in a Twin Cylinder Diesel Engine, Ist International Conference on "New Frontiers in Biofuels, DTU, January 1819, 2010, New Delhi

26. A. Adam, M. Rizalman, N. Atiqah, Y. Kidoguchi, and A. Zafri, Analysis of Straight Vegetable Oil (SVO) Spray Characteristics at End of Injection (EOI), Journal of Medical and Bioengineering (JOMB) Vol. 1, No. 1, September 2012.

27. Samuel T. Jones, Charles L. Peterson, Joseph C. Thompson, Used Vegetable Oil Fuel Blend Comparisons Using Injector Coking in a DI Diesel Engin, An ASAE Meeting Presentation Paper No. 01-6051, July 30 - August 1, 2001. 